\title{
Design de informação e cidade: um exercício embrionário tendo Brasília como cenário
}

\author{
Information Design and city: an embryonic \\ exercise taking Brasilia as a backdrop.
}

Brasília, espaço, design de informação, affordance
Neste artigo apresenta-se um exercício embrionário para a construção de relações entre design de informação e cidade. Parte-se do princípio de que o design de informação é um importante mediador para o uso de ambientes urbanos e a cidade, como meio técnico informacional, tem seu uso potencializado a partir das suas disponibilidades ambientais. Fundamenta-se o artigo a partir de importantes estudos sobre a cidade que pensam os atuais usos urbanos. Para tanto, além dos fundamentos básicos sobre design de informação, buscou-se a leitura de autores sobre a cidade como Lucrécia D’Aléssio Ferrara e David Harvey, sobre espaço técnica e política em Maldonado e Agamben e ainda, investiga-se a teoria da affordance de Norman como contribuição potencial para a relação de design de informação e contexto. Propõe-se um olhar inicial feito a partir de experiência didática pedagógica em sala de aula. Objetiva-se demonstrar como desde o início da graduação é possível pensar a construção de design a partir de contexto e relações.

This paper presents an embryonic exercise for building up relationships between information design and the city. It starts from the principle that information design is an important mediator for the use of urban environments and that the city, as a technical informational media, has its use boosted from its environmental assets. The article is based on important studies on the city that question current urban uses. Thus, besides the basics of information design, the article takes into account authors who discuss the city, like Lucrecia D'Aléssio Ferrara and David Harvey, or space, technique and policies like Maldonado and Agamben, as well as Norman's affordance theory as potential contributions to the relationship between information design and context. An initial look, derived from a pedagogical teaching experience in the classroom, is proposed. The objective is to demonstrate how since the beginning of an undergraduate course it is possible to think about design development from context and relationships. 


\section{Introdução}

Design e arquitetura são elementos de transformação social e ambiental e, assim considerados desde o funcionalismo. Mesmo que a maioria das correntes funcionalistas supervalorizassem a arquitetura, é inegável o impacto que o pensamento metodológico de Walter Gropius implantado na Bauhaus tem até hoje. Ele propôs um pensamento projetual global no qual fosse considerado cada um dos elementos com os quais o homem interage no seu cotidiano. Esses elementos vão desde a tipografia no seu menor corpo até o mais elevado edifício. Por outro, lado aos poucos observa-se que o design potencializa a arquitetura, permite o uso mais adequado de espaços, faz-se presente enquanto mediador entre o urbano e o homem.

A cidade como meio técnico informacional possuiu elementos a serem desvendados cotidianamente. É possível imaginar, na dinâmica da cidade, que muitas pessoas apenas a atravessam, sem tomarem posse dos seus espaços e, outras pessoas, estão presentes naquele lugar pela primeira vez. Portanto o espaço da cidade deve ser mediado e traduzido de forma eficaz e isso pode diminuir acidentes, potencializar usos, trazer pertencimentos.

É com a função de mediação que o design de informação pode operar como um organizador de modo a permitir que os usos urbanos sejam mais efetivos, seguros e lúdicos. Do encontro entre arquitetura e design de informação faz-se cada vez mais presente a transformação do uso de lugares pela sinalização, pela ordenação espacial e também pela re-significação dos edifícios. Esta última se dá principalmente pela passagem das cidades por diferentes funções na dinâmica global.

Cidades antes industriais como São Paulo, hoje precisam modificar o uso de seus espaços para oferta de serviços. São o caso da antiga fábrica Alpargatas que hoje abriga o Campi da Universidade Anhembi Morumbi na zona leste de São Paulo ou mesmo do Sesc Pompéia. Nesses dois casos observa-se o uso de antigas fábricas para alojarem espaços com outras funções sociais e percebe-se que a união entre arquitetura, design e design de informação foram de suma importância para a re-significação do espaço.

Além dos processos de transformação das funções urbanas decorrentes da modificação de uso dos espaços registram-se as forças que resultam em espaços abandonados e em desuso. Modificações causadas pelo capital, desastres ecológicos, tombamentos históricos, alterações urbano geográficas são algumas dessas forças. Na cidade de Salvador, por exemplo, na região do Pelourinho percebe-se uma sinalização em stencil, com os dizeres: "aqui podia morar gente", trata-se de um protesto contra o grande número de prédios tombados, não reformados e abandonados.

O cenário deste artigo é a cidade de Brasília, seu nascimento forçado, seu tombamento histórico, sua população sempre nova e desejante de pertencimento e por fim a potencialidade de uma relação efetiva entre a arquitetura moderna e o design. Será narrada 
a experiência didática e embrionária de re-significação de alguns espaços na capital do país por meio do design gráfico, comunicação visual e design de informação.

O ponto de partida para a experiência didática realizada pelos alunos de Programação Visual 1 foi a leitura do livro Espaços de Esperança (HARVEY 2004: 305-334), nele o autor narra o atual abandono dos centros urbanos em função da especulação imobiliária, de fortes transformações sociais e ainda da falta de reação da população que cada vez mais se contenta com uma experiência de vida pouco significativa diante da cidade. Um dos capítulos mais contundentes é o "O arquiteto Rebelde", trata-se de um verdadeiro convite para olhar a cidade, pertencer a ela, modificá-la, transitá-la e superá-la. Com base nestas provocações de Harvey realizou-se uma experiência didática e estética com a proposta de modificar, por meio do design de informação e comunicação visual, alguns espaços urbanos abandonados ou com pouco uso na cidade de Brasília.

\section{Pensando a cidade de Brasília}

A criação de uma capital no centro do país foi um projeto desejado por muitos presidentes e existem registros da demarcação de seu espaço desde do século XIX (LAURENT 2009: 144). Entretanto, foi na década de cinqüenta que a construção da capital tomou força. Juscelino Kubitschek prometeu fazer do Brasil um país moderno, evoluindo ou crescendo 'cinqüenta anos em cinco'.

O processo anacrônico da construção de Brasília revela uma série de desencontros: a sua construção apressada fez com que a cidade tivesse num primeiro momento uma ocupação forjada e artificial; a pressa em fazer com que a cidade ficasse pronta, se é que é possível fazer isso, fez com que alguns usos pensados não se efetivassem em concordância com aquilo que foi planejado; o homem brasileiro, da tradição rural ou mesmo o da cidade, não havia se modernizado; alguns elementos necessários para o uso da cidade foram preteridos em seu processo, por exemplo a sinalização só foi implementada duas décadas depois e o trânsito de pessoas distancia-se do projeto das calçadas e passagens.

A construção de uma capital moderna faz com que o argumento de Simondon (SIMONDON apud MALDONADO 2012: 153) sobre o fato de não existir pós-modernidade porque nunca ouve sequer a modernidade pareça bem verdadeiro e relevante. De certa forma até hoje registra-se um desencontro entre o Brasileiro e o ambicioso e incompleto projeto moderno da capital.

Por outro lado, ainda hoje, Brasília é um espaço ordenado, funcional, matricial com cheios e vazios. Isto implica dizer que mesmo que o homem para o qual Brasília foi criada já exista ele a ocupa pouco. Em 
1 O termo gentrificação designa a expulsão da população com menor poder aquisitivo dos centros urbanos e dos espaços nos quais existem mais equipamentos de saúde, educação e lazer. algumas situações e, em alguns pontos, a persistência do projeto moderno até afasta esse homem do convívio com todas as esferas da cidade.

\section{Um designer desejante com olhar de arquiteto rebelde}

Com base na experiência de navegar pela cidade, propôs-se aos alunos da disciplina de programação visual 1, do curso de design, o desafio de encontrar os espaços de desesperanças, nos quais a convivência, a relação com a cidade e o entusiasmo pela vida pareciam ter sido perdidos.

A pesquisa fundamentou-se na leitura de diversos autores sobre design, cidade, informação, comunicação, etc.

Iniciou-se com a leitura do já citado texto de Harvey "O Arquiteto Rebelde”, geógrafo e sociólogo, o autor retoma uma discussão espacial já pontuada em diversos textos seus. Harvey denuncia a barbárie urbana, a privatização dos espaços públicos, os intensos processos de gentrificação $0^{1}$ pelos quais as cidades têm passado nas últimas duas décadas e aponta a especulação imobiliária e a ferocidade do capital como principais responsáveis pelo abandono da cidade como espaço de vida, prazer e contemplação.

Depois abordou-se a teoria da affordance a fim de que os alunos compreendessem as disponibilidades ambientais e as possibilidades de re-significação espacial por meio do design de informação. O termo affordance presente no vocabulário de Donald Norman (1990) designa as características contidas nas formas para uma espécie de interação efetiva entre os homens e o ambiente. Norman inspirou sua definição no trabalho do biólogo James J. Gibson. Para Gibson existem disponibilidades ambientais e em função delas é possível reconhecer as relações entre informações ocorridas em um dado meio. Assim, para a experiência realizada na cidade de Brasília, entender quais affordances e disponibilidades cada ambiente da cidade oferece permite potencializá-las por meio do design.

Outra leitura ofertada aos alunos foi o texto "Formas de Vida" de Giorgio Agamben (2015: 13), a escolha de tal aporte se deu como construção conceitual, entendimento do problema e a construção de um olhar mais social pelos estudantes. Agamben afirma que o motivo fim da existência da vida, da bios, é a felicidade e esta só pode acontecer no espaço de troca informacional da cidade. Tal ambiente permite aquilo que o autor chama de espaço da biopolítica, entendendo política como a relação entre humanos e a bio como uma forma de vida específica que ocorre por uma inserção na civita ou na urbes.

\section{Design como transformador dos usos e percepções espaciais}

Na experiência realizada e documentada neste artigo buscou-se um olhar mais interrogador e técnico, no sentido de examinar quais espaços eram menos utilizados, poderiam ter seu uso modificado e 
ofereciam disponibilidades ambientais para tal transformação. Nesta busca, obteve-se excelente resultado ao realizar uma caminhada fotográfica ocorrida entre os dias 18 de março de 2015 e 01 de abril de 2015. Nessas datas foi proposto ao grupo de alunos que andassem pelas cidades do Distrito Federal com o olhar atento de um Arquiteto Rebelde ou de um designer desejante.

Como método propôs-se inicialmente o desvelar de um olhar mais questionador sobre a cidade, navegando por ela, na busca por seus pontos não utilizados e pouco percorridos.

Foram usadas câmeras de filmagem e fotografia como ferramenta de registro e entrevistas para compreender a sensação de pertencimento ou não dos usuários da cidade. Em sala, realizou-se uma série de debates e exposições a fim de perceber as disponibilidades ambientais dos lugares esquecidos e, por fim, promoveu-se uma rodada projetiva para re-significar tais espaços tendo como elemento de transformação a programação visual, a sinalização e o design de informação.

As imagens e informações ganharam formato de uma primeira apresentação, foram mostradas a toda turma. Cada grupo de alunos apresentou seus registros e fez leituras dos lugares capturados. A classe, por sua vez, contribuiu com mais informações sobre os lugares apresentados, narrando experiências pessoais ou de conhecidos sobre cada um daqueles espaços.

Dentre as paisagens urbanas registradas destacaram-se:

- as passagens subterrâneas que cortam o Eixo Rodoviário Norte Sul, pois elas deveriam ser a forma segura de atravessar um agrupamento de rodovias, entretanto permanecem abandonadas, sem iluminação e mais assustam do que asseguram uma boa travessia para usuários;

- as árvores frutíferas da cidade. Em todas as Super Quadras existem jardins arborizados com árvores de todos os tipos, muitas delas são frutíferas. É possível encontrar frutos em praticamente toda a cidade em todos os meses do ano. Entretanto os frutos são desdenhados em função de um não envolvimento ou não pertencimento do usuário com a cidade;

- espaços ideológicos, inicialmente destinados ao convívio mas que pouco convida à construção de relações e, outros espaços que apesar de muito utilizados possuem uma carga ideológica tão forte que torna a convivência pacífica um grande desafio;

- espaços abandonados como caminhos alternativos construídos por moradores mas que revelaram-se verdadeiras armadilhas perigosas pela falta de iluminação e conservação;

- passarelas esquecidas em detrimento de perigosas travessias pela via dos carros;

- praças desertas que necessitam de convites para serem utilizadas, etc. 
Como resultado parcial obtivemos uma série de pequenos projetos, ainda em fase embrionária, que por meio de simulação e modelação digital permitem perceber a importância da sinalização de ambientes e a potência da relação design de informação e cidade.

\section{Desenvolvimento}

Após a escolha dos espaços de re-significação foram definidos oito pontos, sendo que neste artigo por questão de escopo e espaço serão apresentados apenas dois projetos.

Como passos de desenvolvimento dos projetos foi proposto aos alunos: a observação das imagens, a definição do problema a ser solucionado, a construção de um cronograma com etapas bem definidas, o esboço de alternativas, a pesquisa gráfica, de linguagem e de materiais, a geração de alternativas, o refino, a escolha do melhor resultado e por fim a simulação da aplicação por meio de tratamento fotográfico ou modelagem digital.

Observa-se que os alunos da disciplina estão iniciando sua inserção no universo do design de informação, ainda estão cursando a primeira matéria que trata do uso de tipografias, alguns já cursam a disciplina de ergonomia abordando questões de legibilidade e usabilidade. Possuem conhecimentos básicos de representação e uso de cores. Por isso durante a apresentação das alternativas na etapa de ante-projeto foram feitas algumas correções no sentido de orientá-los sobre relação legibilidade, dinâmica da cidade e tempo de leitura. Também foram sugeridas pesquisas sobre formatos gráficos, diagramação, sistemas de grades e cores de acordo com a necessidade de cada grupo.

Dentre os trabalhos desenvolvidos selecionou-se o proposto pela aluna Giovanna Jenkins. O ponto definido por ela como espaço a ser modificado foi a passarela para travessia de pedestres na EPIA (Estrada Parque Industria e Abastecimento). Trata-se de uma passarela sobre uma autopista com velocidade média de $80 \mathrm{~km}$ por horas. A pista constitui-se o limite entre a cidade de Brasília e algumas Regiões Administrativas. No ponto estudado a aluna observou que existem muitos casos de atropelamento em função da preferência dos pedestres pela travessia pela pista. Quando questionadas sobre o motivo da perigosa escolha as pessoas respondiam que pela passarela gastava-se muito tempo. A aluna observou ainda a estratégia do poder público para tentar coibir a travessia pela estrada, construindo uma espécie de cerca de metal que foi modificada pelos transeuntes. Trata-se visivelmente de estratégia e contra estratégia de uso do espaço público.

Giovanna Rocha Jenkins de Lemos adotou como conceito para o seu trabalho a relação tempo e espaço. Seguindo os preceitos da teoria da affordance ela desenvolveu uma estratégia para a captura do olhar do transeunte posicionando mensagens com forte apelo gráfico, aproveitando as possibilidades de percursos ofertadas no 
ambiente. Giovanna calculou o tempo gasto em cada tipo de travessia, colocando-se como co-participante do projeto, ela cronometrou os tempos, observando que a travessia pela passarela era realmente mais longa mas implicava em maior segurança.

Assim, toda construção gráfica elaborada pela aluna tem como conceito o tempo e como recurso gráfico um grafismo desenvolvido a partir das ferragens da passarela. A aluna ainda aborda mensagens trágico-cômicas a fim de surpreender o transeunte. Frases como "Maria queria tempo, perdeu a vida" relacionam-se tanto como o ambiente quanto com os usos realizados pelos usuários.

Em termos de refino gráfico do projeto são observados o cuidado com o tamanho das frases, o posicionamento das placas no espaço físico traçando uma importante estratégia de mídia, com o intuito de capturar cada olhar observando os possíveis locais de posicionamento do usuário.

No próximo subtítulo serão demonstrados os resultados obtidos neste projeto e demais projetos.

Os alunos Francisco Sales de Melo Matias e Kelvim Albuquerque também abordaram a travessia de pedestres, só que escolheram como área as passagens subterrâneas do bairro conhecido como Asa Norte. As passagens permitem aos usuários da cidade atravessarem da parte leste para oeste e vice-versa. Tanto a Asa Norte quanto a Asa Sul são divididas pelo Eixo Rodoviário Norte Sul. Espécie de autopista com quatorze faixas para carros sendo oito com velocidade de $60 \mathrm{~km} / \mathrm{h}$ e $6 \mathrm{com}$ velocidade de $80 \mathrm{~km} / \mathrm{h}$. Esse feixe de ruas é cenário constante de mortes por atropelamento, entretanto faz parte do tombamento da cidade o que não permite a construção de muros, passarelas, ou qualquer outra estratégia para coibir a arriscada travessia.

No projeto original da cidade, foram pensadas travessias subterrâneas conectando as partes leste a oeste, entretanto elas necessitam de cuidados constantes com a limpeza e a iluminação. São abrigo de usuários de drogas e cenário constante de assaltos, por isso o seu uso é cada vez menor. Uma das estratégias traçadas pelos pensadores da cidade para inibir a depredação é exatamente o seu uso constante. Nesse sentido Francisco e Kelvim propuseram divulgar a travessia subterrânea, apropriando-se do humor e brincando com a possibilidade da construção de uma metáfora de metrô. Não existe metrô na Asa Norte e os estudantes aproveitaram a semelhança, as disponibilidades ambientais do lugar para sinalizar as passagem como estações e trens de metrô. 


\section{Resultados e resumo dos projetos}

\section{PROJETO Vá de Passarela}

O Projeto Vá de Passarela idealizado pela aluna Giovanna Jenkins tem como foco a travessia de pedestres em vias de trânsito rápido. O objetivo foi criar uma misto entre campanha de conscientização e projeto de sinalização para que a população seja incentivada a atravessar pela passarela e seja informada sobre os prejuízos de atravessar pela via.

Figura 1 Vista área da Passarela da Candangolândia na EPIA.

(Fonte: www.google.maps.com).

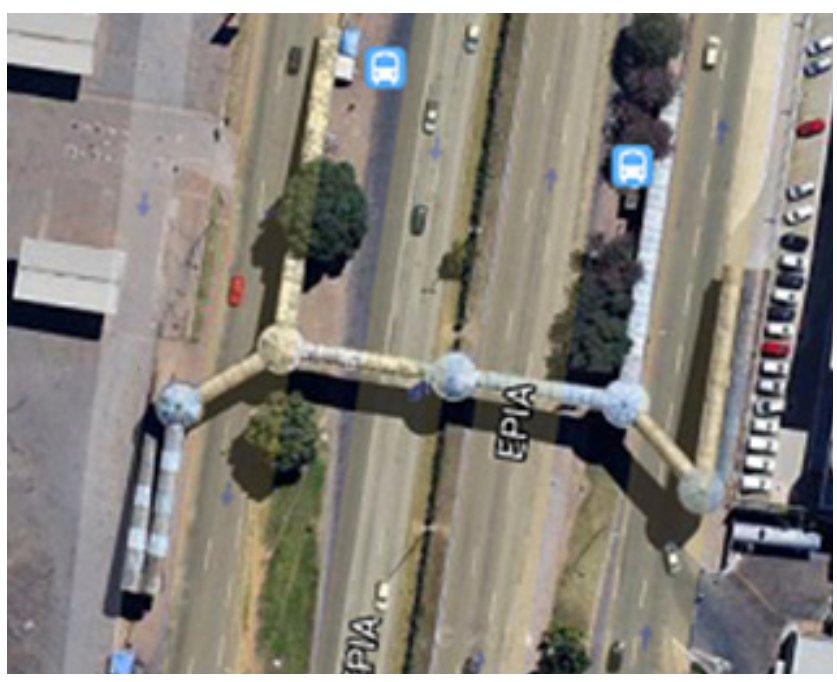

A figura 1 mostra a dimensão da passarela a ser sinalizada. Os pictogramas informam os locais de ponto de ônibus e consegue-se ainda perceber os percursos possíveis neste trajeto.

Figura 2 Capa do Projeto “Vá de passarela!”, por Giovanna Jenkins

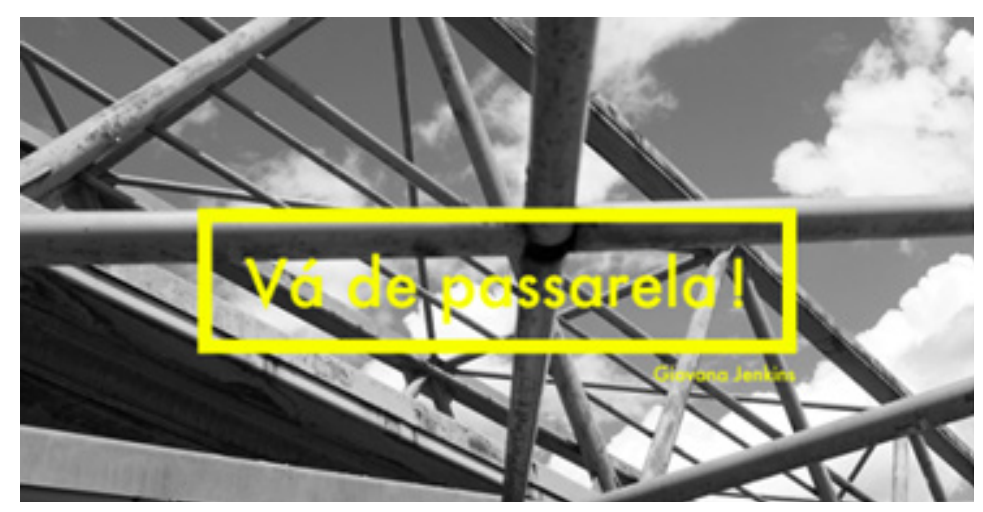

Na figura 2 a capa do trabalho da aluna indica o uso de cores fortes e contrastantes com o ambiente. Em todo caso foi sugerido à aluna que evitasse a aplicação do amarelo sem bordas de contraste pois da forma como a informação foi colocada na capa a vibração causada pela cor 
amarela dificulta um pouco a leitura. A justificativa é que trata-se de uma capa e na sinalização de fato a cor utilizada para as informações principais foi azul sobre branco ou amarelo sobre azul.

Figura 3 Poster “Tempo de Percurso ”, porGiovanna Jenkins

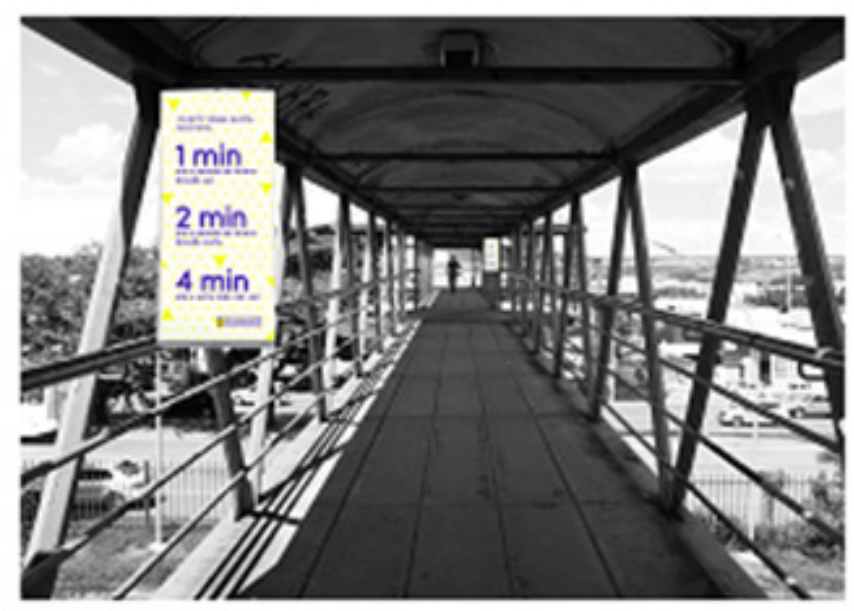

No poster "Tempo de Percurso" a aluna trabalha com o principio da Legibilidade e adota a hierarquia de informação para que a mensagem principal, informação sobre o tempo de travessia, seja percebida de modo rápido pelo leitor. Este poster compõe com outros ao longo da passarela, eles formam uma espécie de relógio natural que informa quanto tempo, a partir daquele ponto, o pedestre gastará para fazer a travessia completa. Observa-se que a informação é disposta de modo simples. Trabalha-se a clareza visual do texto, baseada na hierarquia de tamanhos, no contraste entre as cores, no espaçejamento dos blocos de informação.

A tipografia utilizada pela aluna foi a Quiksand e suas variações, como cor escolheu-se um pantone Violet U e o pantone Yellow U ambos com a propriedade fotoluminescente que permite ao pigmento receber informação solar durante o dia e emitir iluminação durante a noite. Tal escolha permite ao conjunto gráfico ser observado com clareza em qualquer hora do dia. Observa-se ainda o trabalho com camadas de informação e camadas gráficas, as camadas de informação foram utilizadas como uma espécie de aproximação com o leitor, informações com tamanhos diferentes para serem lidas em diferentes posicionamentos e as camadas gráficas permitiram a construção ter instâncias de dialogo com o ambiente, como se observa na representação da malha triangular que dialoga com as ferragens da passarela, bem como com os diferentes tamanhos tipográficos que dialogam com o usuário, detalhando o tempo de travessia. 
Figura 4 Outdoor "João queria tempo", por Giovanna Jenkins

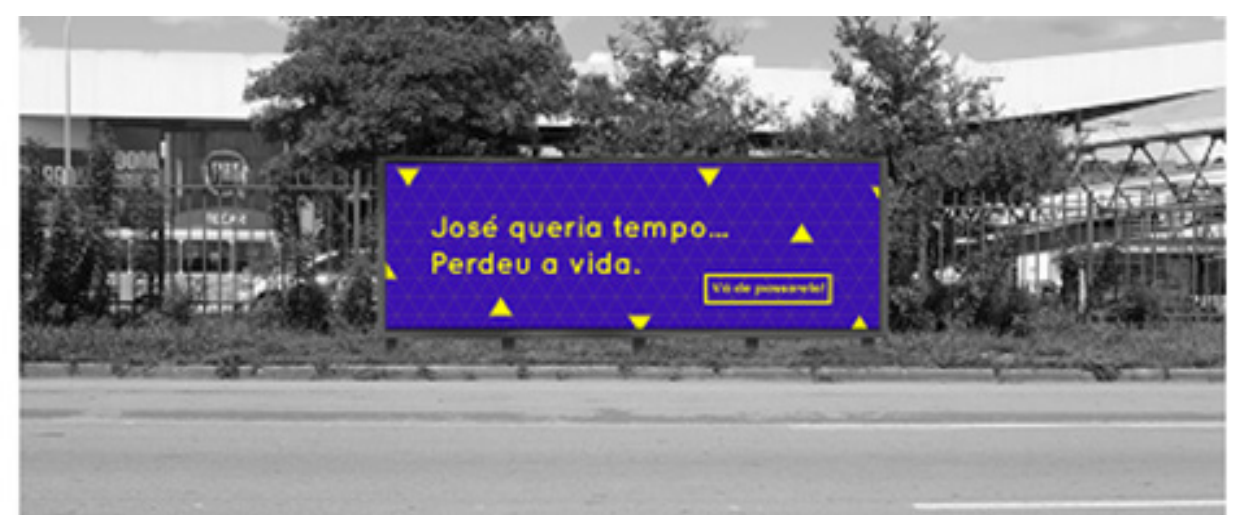

No Outdoor "João queria tempo", Giovanna trabalha a construção de uma narrativa espacial, a sugestão de posicionamento da placa em frente ao ponto do ônibus e possível local da descida do transeunte captura o olhar do pedestre. Essa estratégia obedece a teoria das affordances de Norman pois permite ampliar o potencial de visualização da informação em função do seu posicionamento no espaço.

\section{PROJETO Passagem Subterrânea}

O Projeto Passagem Subterrânea foi construído tendo como principal conceito a mensagem cômica de que as passagens são o Metrô da Asa Norte. Além disso apropria-se do visual moderno presente nas construções do espaço para compor um sistema informacional. Tal sistema opera com elementos gráficos recorrentes em projetos de design gráfico moderno. Por exemplo, o conjunto tipográfico escolhido pela dupla utiliza-se da família tipográfica PF Din text. Família construída na década de 30 com linhas retas e características funcionais. Em termos cromáticos a opção foi pelas não cores, elegeram o preto e branco para contrastar com o ambiente que já possuiu muitos grafismos, muito verde em seu entorno e muitas cores. Assim, o preto e branco operam como uma ilha de neutralidade dentre de um vasto universo cromático. 
Figura 5 Placa de Sinalização. por Francisco Sales de Melo Matias e Kelvim Albuquerque

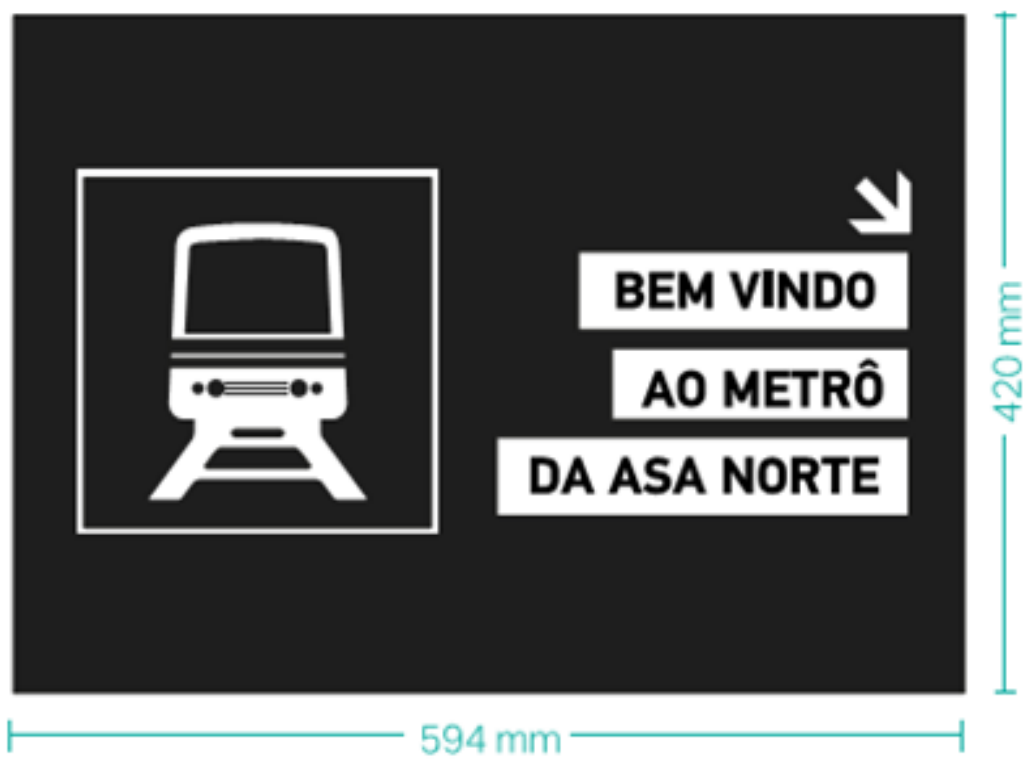

Figura 6 Placas de Sinalização, por Francisco Sales de Melo Matias e Kelvim Albuquerque

USE AS PASSAGENS. A VIDA TAMBÉM PASSA POR AQUI
SUA VIDA É MAIS IMPORTANTE

CONTINUE USANDO AS PASSAGENS
POR QUE SE ARRISCAR POR CIMA?

ATRAVESSE SEM RISCOS

USE AS PASSAGENS SUBTERRÂNEAS

\section{POR AQUI LEVA EM MÉdIA 2 MINUTOS}

As placas de sinalização (figuras 5 e 6 ) desenvolvidas utilizam fontes em caixa alta, com mensagens textuais sobre a travessia. Foi explicado aos alunos que todos os textos em caixa alta dificultam o reconhecimento de palavras e que grandes blocos de texto assim denunciam uma dificuldade em decodificar a informação, entretanto observa-se uma necessidade presente em alunos de início de curso para conseguir alinhar e criar blocos e a pouca preocupação com a legibilidade. De qualquer forma o exercício de construção das placas permitiu testar a pouca funcionalidade do conjunto. 
Figura 7 Poster "Lambe-lambe", por Francisco Sales de Melo Matias e Kelvim Albuquerque
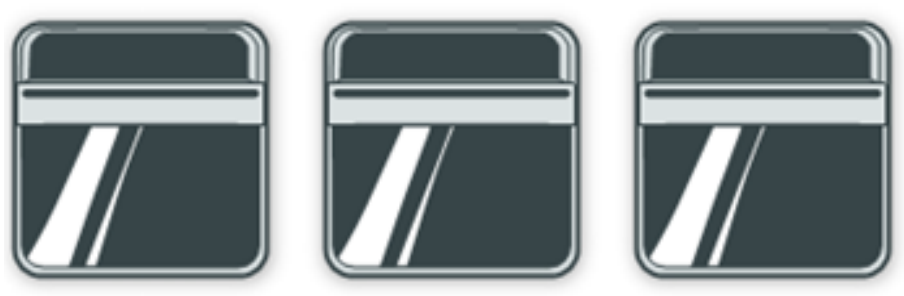

Material:

\section{Poster Lambe-lambe}

O poster Lambe-lambe (figura 7) constituiu um elemento lúdico do conjunto, trata-se da simulação das janelas de metrô que uma vez fixadas nas passagens dariam a impressão de se estar em um vagão do trem. Entretanto também foi ensinado aos alunos que a grande massa de preto e o pouco contraste da peça dificultaria ainda mais a iluminação local que já é prejudicada.

Figura 8 Aplicação de faixas e sinalização em passagem subterrânea na Asa, aspecto do projeto de Francisco Sales de Melo Matias e Kelvim Albuquerque

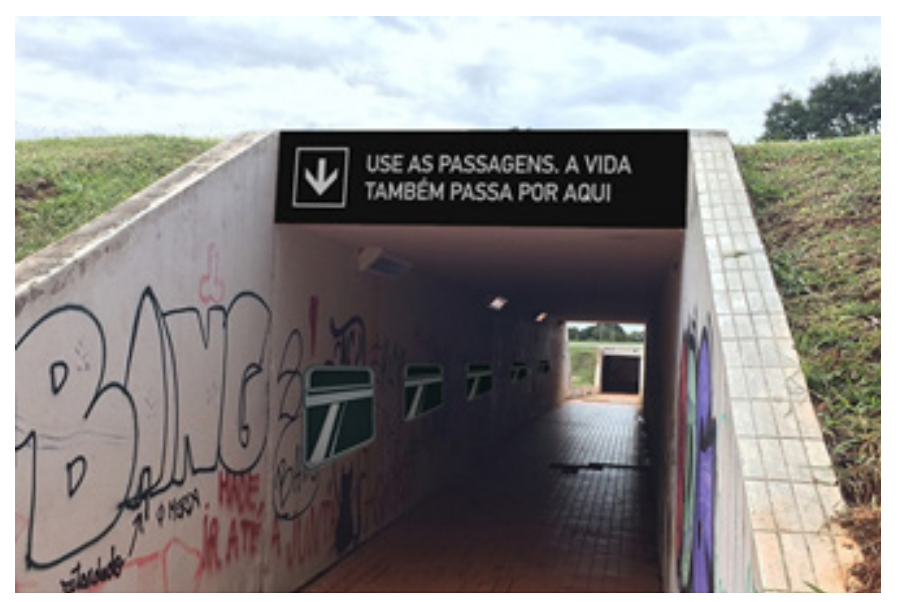

Uma vez simulada a aplicação no ambiente (figura 8), foi possível perceber que embora os alunos tenham observado as disponibilidades ambientais, criado um conceito para o exercício proposto, desenvolvido suas peças, as mesmas não foram eficientes no sentido de incentivar o uso das passagens subterrâneas, em parte porque as passagens necessitam de um trabalho conjunto mais efetivo entre arquitetura e design e em parte porque o design de informação não foi utilizado em toda a sua potência de transformação. 


\section{Conclusão}

Apesar do apelo estético, alguns estudantes entenderam a atividade como uma forma de denúncia do modo como o projeto arquitetônico de Brasília e seu tombamento cerceiam a vida. Com esse olhar mais crítico percebeu-se que a possibilidade da interação entre a arquitetura e o design de informação permite modificar situações muito problemáticas. Pontua-se aqui o caso das passarelas. Não permitidas pelo tombamento do plano piloto e construídas em seu limite com um objetivo muito mais estilístico do que funcional. Acarretando um percurso muito extenso o que tenciona o transeunte a atravessar pela pista em detrimento do uso das passarelas. Por outro lado o uso de materiais não indicados resulta em depredação colocando em risco a vida do usuário.

Os espaços de uma cidade só funcionam e só fazem sentido quando utilizados por seus moradores. Alguns desses espaços possuem uma certa disponibilidade para exercerem algumas funções no dia a dia. Outros, embora tenham sido criados com uma finalidade, não conseguem atrair o transeunte da cidade, passam esquecidos, tornam-se lugares perigosos e abandonados.

O design sozinho como elemento construído isoladamente desconsiderando público e ambiente não permite modificar o uso de tais espaços, acaba por ser apenas mais um elemento disputando a atenção do usuário. Por outro lado ao observa-se as disponibilidades ambientais, as possibilidades de legibilidade, a construção de um design de informação eficiente, bem organizado, com uso coerente de cores, tipografias e formatos é possível potencializar em muito o uso satisfatório do ambiente urbano.

Os exemplos mostrados neste artigo são experimentos iniciais de alunos no começo de seu percurso para tornarem-se designers, entretanto o exercício da contextualização e construção de relações permite perceber que as construções e peças de design não funcionam sozinhas elas estão inseridas em dinâmicas de uso, relação com espaço, adequação de formatos e suportes e só constituirão verdadeiros sistemas de design quando relacionadas com os elementos que compõe o ambiente humano.

\section{Agradecimentos}

Aos alunos da disciplina de Programação Visual 1, especialmente Giovanna Rocha Jenkins de Lemos, Francisco Sales de Melo Matias e Kelvim Albuquerque Ferreira.

Ao Ministério da Cultura - MinC e Decanato de Extensão da Universidade de Brasília pelo financiamento da pesquisa sobre Cidade e Economia Criativa dentro do Observatório de Economia Criativa da UnB. 


\section{Referências}

AGAMBEN, Giorgio. Meios sem fim: notas sobre política. Belo Horizonte: Autêntica editora, 2015 .

FERRARA, Lucrécia D’Aléssio. A estratégia dos signos. São Paulo: Perspectiva, 2009.

GIBSON, James J. The ecological approach to the visual perception. New Jersey: Lawrence Erlbaum Associates, Inc. Publishers, 1986.

HARVEY, David. Espaços de esperança. São Paulo: Loyola, 2004.

LAURENT, Vidal. De nova Lisboa à Brasília: a invenção de uma capital (século XIX -XX). Brasília: UnB, 2009.

LIDWELL, Eilliam, HOLDEN, Kristina e BUTLER, Jill. Princípios universais do design. Porto Alegre: Bookman, 2010.

LUPTON, Ellen e PHILLIPS, Jennifer Cole. Novos fundamentos do design. São Paulo: Cosac Naify, 2008.

MALDONADO, Tomás. Cultura, sociedade e técnica. São Paulo: Blucher, 2012. NORMAN, Donald. The design of everyday things. Doubleday, 1990.

\section{Sobre a autora}

Fátima Aparecida dos Santos

Doutora, UnB < designfatima@uol.com.br>

Artigo recebido em 20 set. 2015,

aprovado em 21 set. 2015. 